\title{
D region HF radar echoes associated with energetic particle precipitation and pulsating aurora
}

\author{
S. E. Milan ${ }^{1}$, K. Hosokawa ${ }^{2}$, M. Lester ${ }^{1}$, N. Sato ${ }^{3}$, H. Yamagishi ${ }^{3}$, and F. Honary ${ }^{4}$ \\ ${ }^{1}$ Department of Physics and Astronomy, University of Leicester, Leicester LE1 7RH, UK \\ ${ }^{2}$ Department of Information and Communication Engineering, University of Electro-Communications, Tokyo, Japan \\ ${ }^{3}$ National Institute of Polar Research, Tokyo, Japan \\ ${ }^{4}$ Department of Communications Systems, University of Lancaster, Lancaster LA1 4WA, UK
}

Received: 27 October 2007 - Revised: 16 May 2008 - Accepted: 4 June 2008 - Published: 14 July 2008

\begin{abstract}
Milan et al. (2001) identified a class of narrow, slow-moving HF radar backscatter echoes which originate between altitudes of 80 and $100 \mathrm{~km}$, the ionospheric D- and lower E-regions. These echoes appeared to be associated with the occurrence of pulsating aurora, which are known to be created by energetic electrons capable of penetrating to $D$ region altitudes. In this study we show that these echoes are observed in tandem with enhancements in cosmic noise absorption (auroral absorption), additional evidence that energetic $(>30 \mathrm{keV})$ particle precipitation is responsible for generating the irregularities from which a radar can scatter. In addition, we show that the $\mathrm{D}$ region backscatter echoes occur predominantly in the post-midnight sector during substorm recovery phase, in common with auroral absorption events and pulsating aurora.
\end{abstract}

Keywords. Ionosphere (Auroral ionosphere; Ion chemistry and composition; Particle precipitation)

\section{Introduction}

The SuperDARN radars (Greenwald et al., 1995; Chisham et al., 2007) are designed to detect HF radiowave coherent backscatter from ionospheric plasma irregularities at $\mathrm{F}$ region altitudes which act as tracers of the polar ionospheric convection pattern. However, these radars are also able to detect backscatter from lower altitudes, mainly from irregularities in the E region (e.g. Milan and Lester, 2001; Milan et al., 2003). E region scatter can be considered as clutter in the radar observations as the irregularities drift at speeds depressed below the $\mathrm{F}$ region convection speed. On the other hand, study of the characteristics of these echoes, observed by both HF and VHF radars, can reveal much about the complex collisional plasma physics which occurs at such alti-

Correspondence to: S. E. Milan

(steve.milan@ion.le.ac.uk) tudes (e.g. Haldoupis, 1989; Milan and Lester, 2001; Milan et al., 2004). The SuperDARN radars can discriminate between $\mathrm{F}$ region and lower-altitude backscatter by interferometric means (e.g. Milan et al., 1997a).

At even lower altitudes, there are at least two known mechanisms by which HF radar returns can be observed from the mesosphere or D region, but these are not necessarily coherent scatter processes. The ablation of meteors allows backscatter from the resulting plasma trails, and as these trails are thought to drift with the neutral wind, meteor echoes are useful for the investigation of mesospheric tides. Meteor echoes appear as "grainy near-range echoes" (Hall et al., 1997) in SuperDARN observations, as meteor trails are small in comparison to a radar range cell. Also, some backscatter features have been associated with the occurrence of Polar Mesospheric Summer Echoes observed by MST radars (e.g. Ogawa et al., 2003), which are believed to be caused by charged aerosols near the cold summer mesopause.

This paper investigates a proposed third mechanism for the generation of $\mathrm{D}$ region echoes. First identified by Milan et al. (2001), based upon 30 min of observations, spatiallyextensive regions of $\mathrm{D}$ region echoes appeared to be associated with pulsating aurora. In addition to their altitude of origin, the echoes observed were unusual in that their spectra were exceptionally narrow, having spectral widths less than $20 \mathrm{~m} \mathrm{~s}^{-1}$, which is in contrast to the bulk of E region spectra which have widths in excess of $100 \mathrm{~m} \mathrm{~s}^{-1}$. Indeed, such spectral widths are comparable to those of meteor echoes, in which the decorrelation of the radar auto correlation function is governed by the rate of ambipolar diffusion of the plasma trail rather than ionospheric instability growth and decay times (Hall et al., 1997; Milan et al., 2001). The energy spectrum of precipitating electrons associated with pulsating aurora is expected to be relatively hard (Stenbaek-Nielsen and Hallinan, 1979), the bulk of the energy flux being carried by electrons between 5 and $40 \mathrm{keV}$ (Sandahl et al., 1980) which

Published by Copernicus Publications on behalf of the European Geosciences Union. 


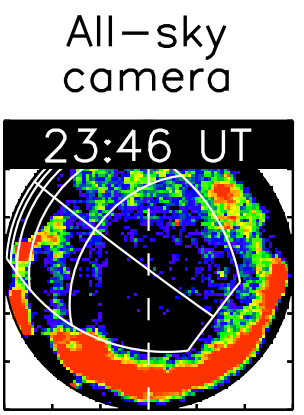

Riometer absorption
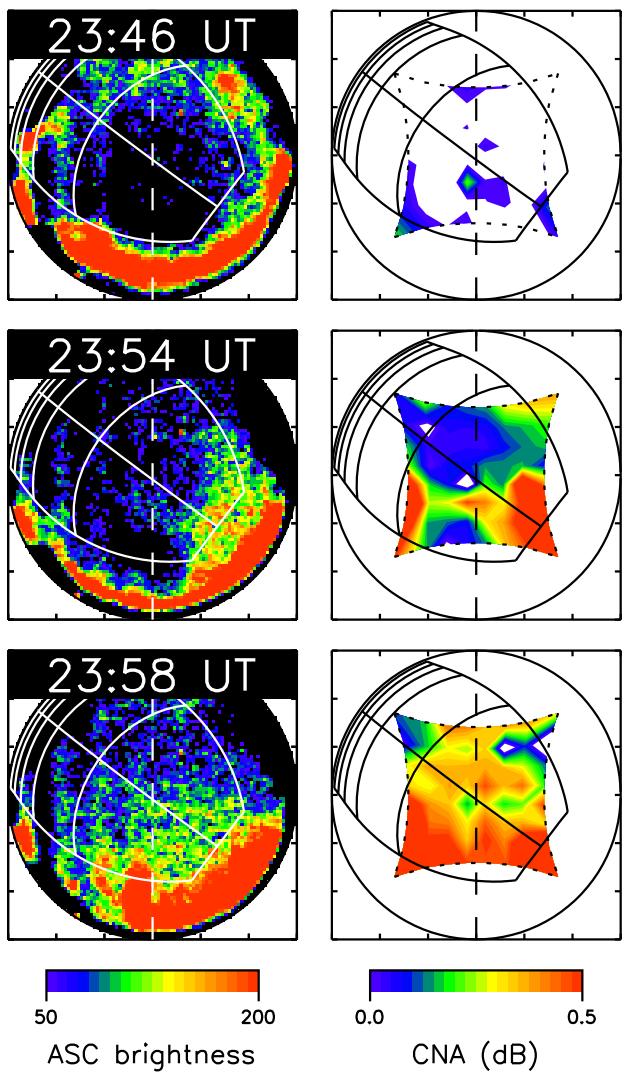
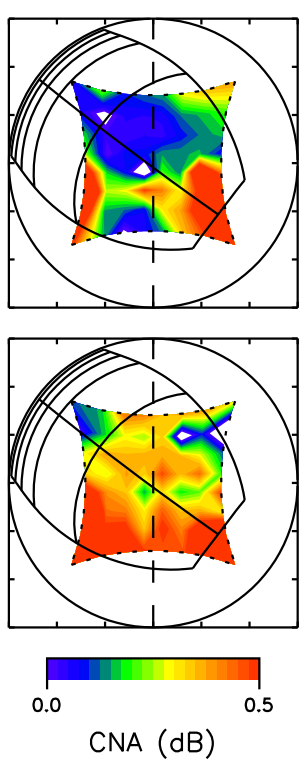

Radar echo width
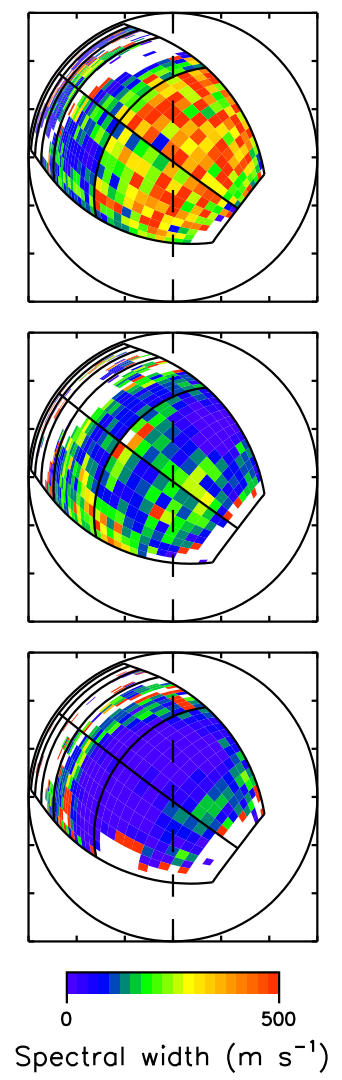

Radar altitude
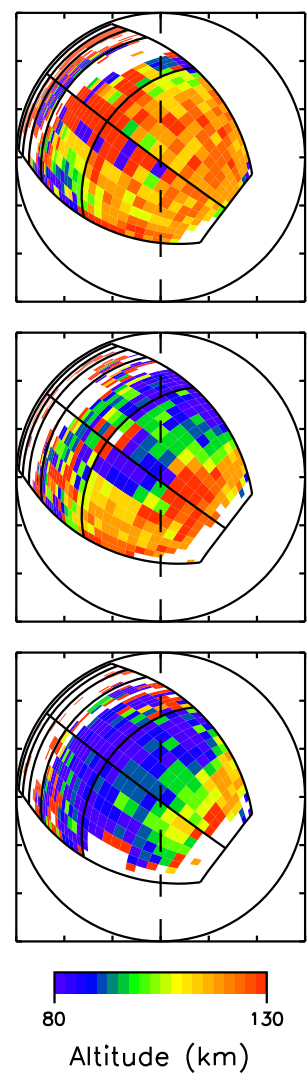

Fig. 1. (Left column) All-sky camera snapshots of the auroral configuration over Tjörnes, Iceland, at three times on the 13 September 1999. Magnetic north and east are to the top and left, respectively. (Second column) Cosmic noise absorption measured by the Tjörnes imaging riometer. (Third column) The spectral width of E region backscatter echoes detected by the Pykkvibær radar. (Right column) The altitude from which the echoes originate.

produce excess ionization at altitudes below the E region peak. Milan et al. (2001) speculated that spatially-structured precipitation - and the resulting spatially-structured electron density enhancement - could allow backscatter from these low altitudes, and that the decay of the irregularities would be governed by the ambipolar diffusion rate.

In this paper we investigate this mechanism further by using riometer observations of cosmic radio noise absorption (CNA) to diagnose enhancements of the $\mathrm{D}$ region electron density. We show that the pulsating aurora from the original study of Milan et al. (2001) are indeed associated with enhanced CNA, consistent with energetic particle precipitation. We further show that during an additional $18 \mathrm{~h}$ of riometer observations, from 3 separate nights, other occurrences of cosmic noise absorption are associated with detection of this low-altitude echo population.

\section{Observations}

We begin by re-examining the interval first studied by Milan et al. (2001), that is 23:30 to 24:00 UT, 13 September 1999. We employ observations from the SuperDARN radar located at Pykkvibær in Iceland, built and operated by the University of Leicester (see e.g. Milan et al., 1997b), when it was operating in "myopic" mode, that is with $15 \mathrm{~km}$ range gates rather than the usual $45 \mathrm{~km}$, to focus specifically on the near-range field-of-view where $\mathrm{E}$ region backscatter is typically seen (e.g. Milan and Lester, 2001). Sixteen beams are sounded at a radar operating frequency of $10 \mathrm{MHz}$, and the backscatter returns gated into 75 range cells, with a range to the first gate of $180 \mathrm{~km}$, and a maximum range of $1305 \mathrm{~km}$. Under the near-range field-of-view of the radar is the Icelandic village of Tjörnes which acts as one of the observing locations for occasional all-sky camera (ASC) campaigns run by the National Institute of Polar Research (NIPR), Japan. Tjörnes is also the location of a $30 \mathrm{MHz}$ imaging riometer, run on a continuous basis by NIPR. 
The left-hand column of Fig. 1 shows a sequence of three images taken by the Tjörnes white-light ASC. The images are aligned with magnetic north to the top and magnetic east to the left. The brightness scale is in uncalibrated, arbitrary units. The central N-S meridian of the images, along which we will compare measurements from different instruments, is indicated by a vertical dashed line. The main feature to note in all three images is the presence of a discrete auroral arc to the south of the ASC zenith. Superimposed on the images is the location of the Pykkvibær radar field-ofview projected to an altitude of $100 \mathrm{~km}$, including the edges of the field-of-view, the boresite, and the location of every 15 th range gate. The second column shows CNA measurements from the Tjörnes riometer (projection independent of altitude). The third and fourth columns show the corresponding radar data, the backscatter spectral width and the altitude of backscatter determined by interferometric techniques, respectively.

In the first image of the sequence, 23:46 UT, dim auroral emission is observed to the west of the radar field-of-view (to the right), north of the discrete arc. Although not apparent from the captured images, this region of auroral emission comprises irregular patches of pulsating aurora. At this time the radar backscatter originates from typical $\mathrm{E}$ region altitudes, 100 to $120 \mathrm{~km}$, and the backscatter echoes have spectral widths of the order of 100 to $500 \mathrm{~m} \mathrm{~s}^{-1}$, typical of E region backscatter (e.g. Milan and Lester, 2001). In the second and third images, 23:54 and 23:58 UT, the region of pulsating aurora expands eastwards (towards the left) across the radar field-of-view. Simultaneously, the radar echoes decrease in spectral width to less than $20 \mathrm{~m} \mathrm{~s}^{-1}$, and the altitude of backscatter decreases to between 80 and $100 \mathrm{~km}$. These were the findings presented by Milan et al. (2001). In addition we show the corresponding riometer measurements. If the pulsating aurora do indeed deposit ionization at low altitudes, such that backscatter echoes are observed from the lower-E and D regions (henceforth, for brevity we refer to these just as D region echoes), then we expect an increase in riometer absorption. This is just what is observed, absorption increasing from 0 to $0.6 \mathrm{~dB}$ across the riometer field-ofview, especially in the southern portion. This lends credence to our interpretation that the occurrence of the low-altitude backscatter is caused by the deposition of energetic particles in $\mathrm{D}$ region and the associated secondary ionization.

These observations are reiterated in Fig. 2, which shows the time-evolution of the auroral, riometer, and backscatter observations between 23:30 and 24:00 UT. Panel (a) shows a keogram of the auroral observations from the north-south meridian of the field-of-view of the ASC. At the start of the interval an auroral arc is seen to the north, though this fades at 23:42 UT. The auroral arc to the south of Tjörnes identified in Fig. 1 is apparent throughout the interval, though this brightens at 23:43 UT, corresponding to the onset of a substorm identified in concurrent magnetometer traces. Pulsating aurora appear to the north of this arc after 23:55 UT, extending
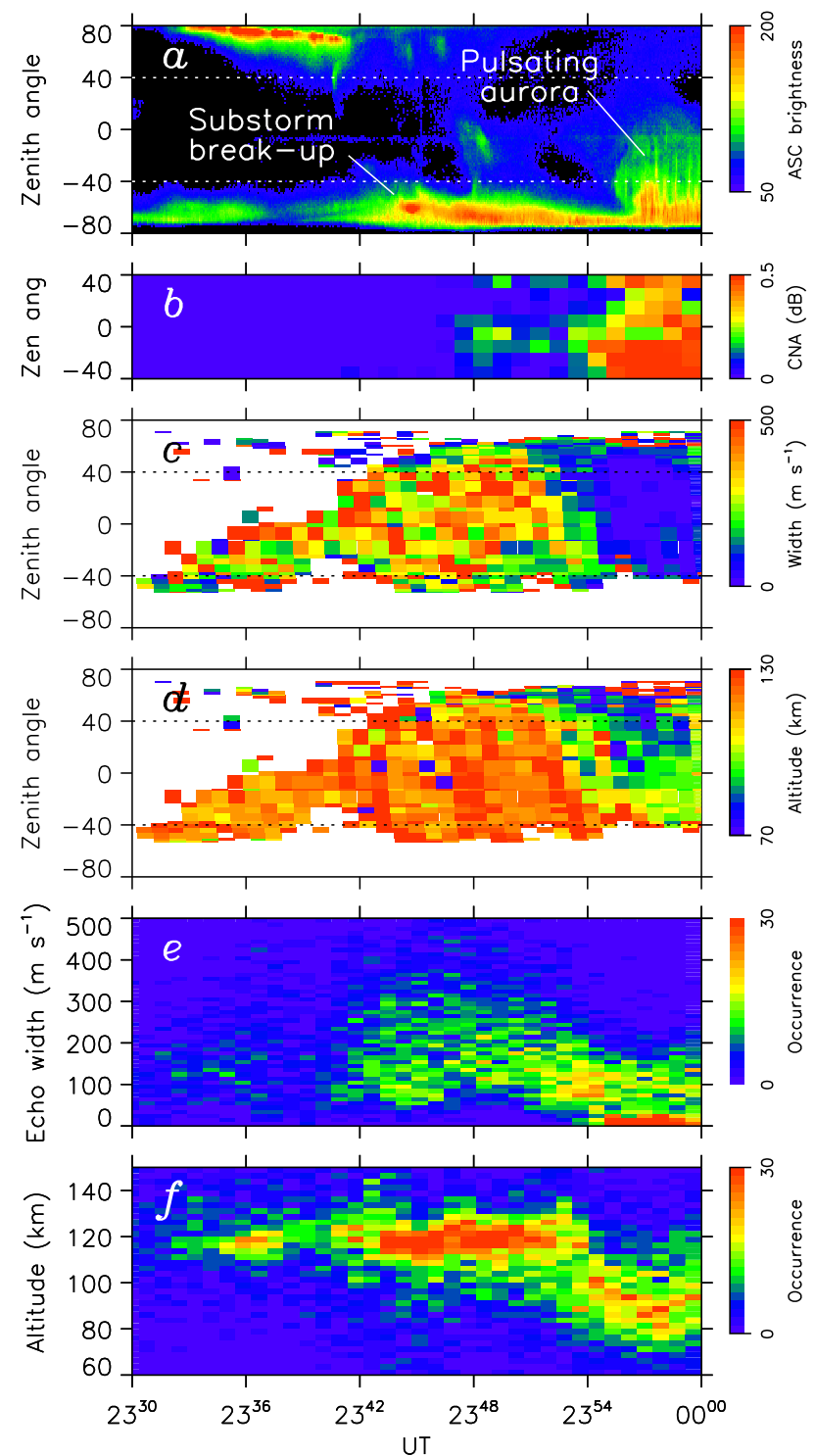

Fig. 2. (a) Keogram of the auroral observations from the geomagnetic meridian of the ASC field-of-view, between 23:30 and 24:00 UT on the 13 September 1999. (b) Cosmic noise absorption along the same geomagnetic meridian. (c) Radar observations of radar echo width, projected along the ASC meridian. (d) Estimate of the altitude of the backscatter volume, projected along the ASC meridian. (e) Temporal evolution of the distribution of spectral widths of the radar echoes observed. (f) Corresponding altitude distribution.

up to the zenith of the camera, with quasi-periodic enhancements in brightness with timescales ranging from a few seconds to a few tens of seconds (see below). Panel (b) shows the CNA measurements of the riometer taken along the keogram meridian. The absorption increases from 23:48 UT, though most markedly after 23:55 UT, associated with the appearance of the pulsating aurora. The absorption is greatest in the southern portion of the field-of-view, coincident 


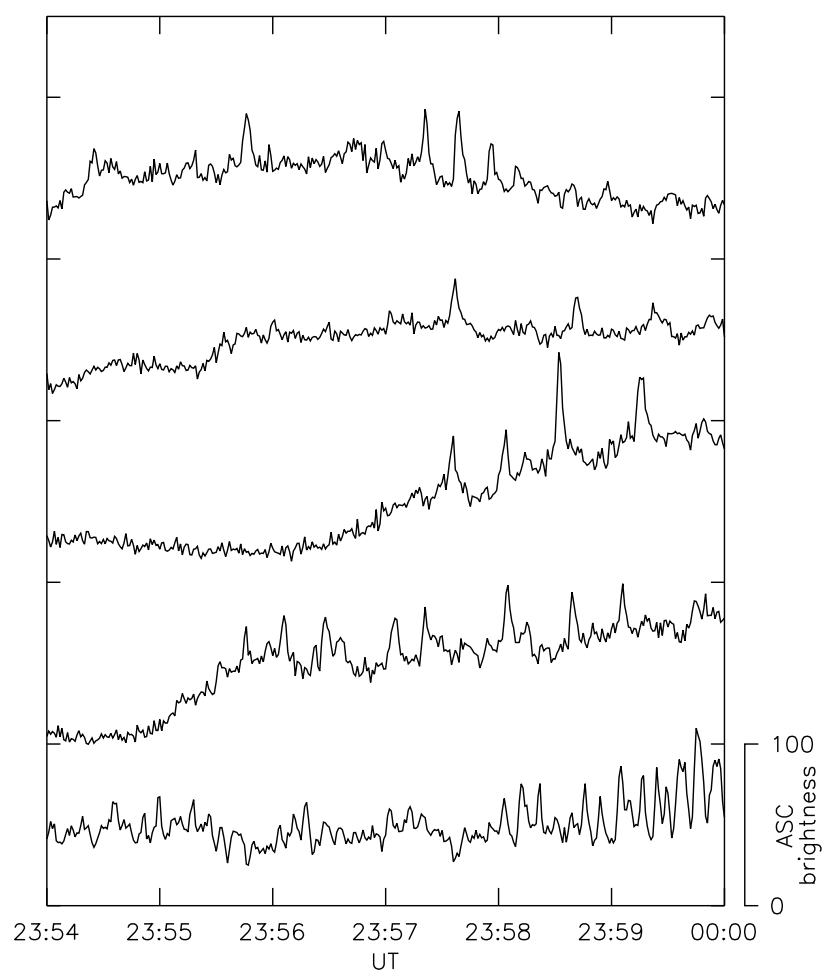

Fig. 3. Variations in the observed auroral brightness at five points within the all-sky camera field-of-view, allowing the temporal variations associated with the pulsating aurora to be determined. The curves have been offset for clarity.

with the pulsating aurora, though absorption is also present polewards of this. Panel (c) shows the radar spectral width measurements, again projected along the keogram meridian. There is a clear and sudden decrease in the spectral widths at 23:54 UT, coincident with the appearance of the pulsating aurora and the increase in CNA. Panel (d) shows the associated altitude of the backscatter volume, showing the sudden decrease in backscatter altitude at 23:54 UT. Panel (e) shows the distribution of spectral widths within the backscatter within the near-range field-of-view of the radar, that is in all beams and for range gates 0 to 29 . The overall occurrence of backscatter echoes increases after 23:42 UT, apparently associated with the increase in brightness of the southern arc at this time. Before 23:54 UT the distribution of widths is broad, encompassing values between 100 and $400 \mathrm{~m} \mathrm{~s}^{-1}$. This drops after 23:54 UT to widths below $150 \mathrm{~m} \mathrm{~s}^{-1}$, with most echoes having widths less than $20 \mathrm{~m} \mathrm{~s}^{-1}$. Finally, panel (f) shows the number of echoes observed at differing altitudes. Prior to 23:54 UT these occur predominantly near $120 \mathrm{~km}$. Subsequently, the altitude of backscatter drops abruptly to between 80 and $100 \mathrm{~km}$. Hence, Fig. 2 shows a clear association between the appearance of pulsating aurora, the occurrence of CNA, and the appearance of a low-altitude, narrow-spectra backscatter population. At the same time, the pre-existing E region echo population disappears.
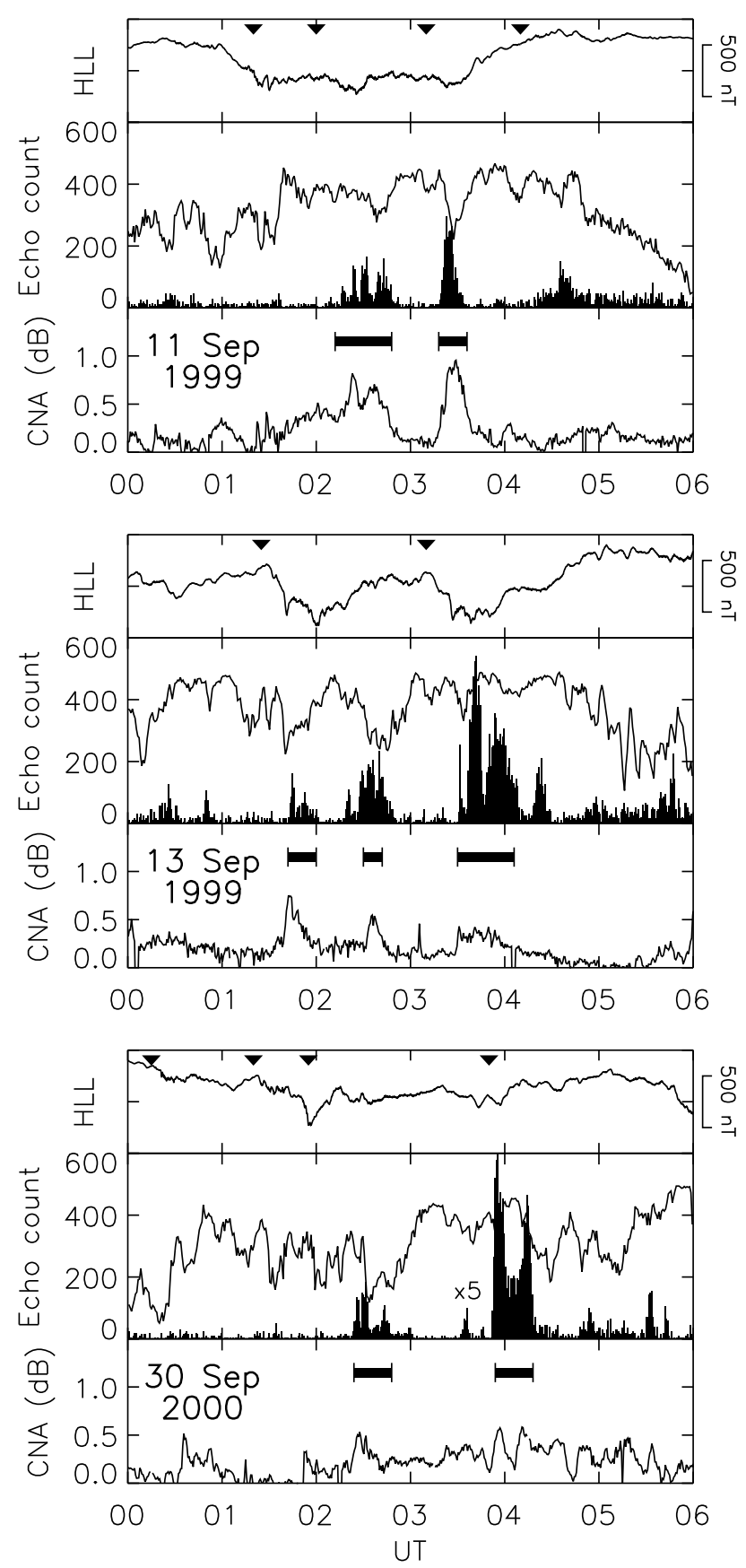

Fig. 4. Three examples of the correspondence between riometer absorption and the occurrence of $\mathrm{D}$ region radar echoes. In each set of three panels: (upper panel) the $H$ component magnetic field measured by the HLL magnetometer of the SAMNET network; triangles indicate the times of significant Pi2 activity; (middle panel) the total number of E region echoes seen (solid curve) and the number of $\mathrm{D}$ region echoes (black histogram, values multiplied by 5); (lower panel) the riometer absorption measured while it was operating in a vertical wide-beam mode. 
Figure 3 presents time series of the brightness at 5 selected points within the ASC field-of-view for the period associated with pulsating aurora, 23:54 to 24:00 UT; the curves have been offset for clarity. Each curve shows transient quasiperiodic enhancements in the brightness, with periods ranging from a few seconds to a few tens of seconds. This indicates that the variations in brightness at different points within the aurora occur independently of each other, demonstrating the patchy nature of the pulsations described above.

To determine the reproducibility of these observations, we examined other runs of the myopic mode on the Pykkvibær radar which occurred on 12 nights in September 1999 and September 2000. E region backscatter is usually observed by the radar between 18:00 and 06:00 UT (MLT $\approx \mathrm{UT}+0.5$ ) as at these times the auroral electrojets are located in the near-range field-of-view. Hence, myopic runs are usually scheduled between these times. Figure 4 presents three examples of radar and riometer observations from 00:00 to 06:00 UT on 11 and 13 September 1999 and 30 September 2000. In each case, the middle panel shows the total number of backscatter echoes observed in the first 30 gates of the field-of-view of the radar (solid curve) where $\mathrm{E}$ region backscatter typically occurs (maximum possible is 30 gates $\times 16$ beams $=480$ cells). Superimposed on this is the occurrence of backscatter echoes which originate below an altitude of $100 \mathrm{~km}$ and which have a spectral width less than $20 \mathrm{~m} \mathrm{~s}^{-1}$ (filled bars), the characteristics of the new backscatter population expected from the previous discussion. The number of such echoes has been multiplied by 5 for clarity. In each case, the bottom panel shows the CNA measurements from the Tjörnes riometer operating in a wide-beam, vertically-sounding mode. The top panel shows the H component magnetogram from the SAMNET magnetometer station colocated with the Iceland radar site, HLL, with triangles showing the times of significant Pi2 activity indicating the onset of substorm activity.

In each example we find between 2 and 4 main episodes of low altitude backscatter. Most of these occur in tandem with absorption of the cosmic noise background observed by the riometer; coincident events are marked by horizontal bars for clarity. On occasions these are also associated with overall decreases in the number of $\mathrm{E}$ region echoes observed, as might be expected if the radar signals are also being attenuated in the enhanced D region. These results graphically demonstrate the association between enhancements of the $\mathrm{D}$ region electron density, giving rise to auroral absorption of the cosmic noise background, and the observation of backscatter echoes from $D$ region altitudes. In each case, the magnetogram indicates a substorm bay (a negative excursion associated with the substorm westward electrojet) and Pi2 activity commencing a few 10 s of minutes prior to the event, suggesting that the CNA and D region backscatter are substorm recovery phase phenomena.

It is interesting to note that although runs of the myopic mode usually took place from 18:00 to 06:00 UT, most sig-
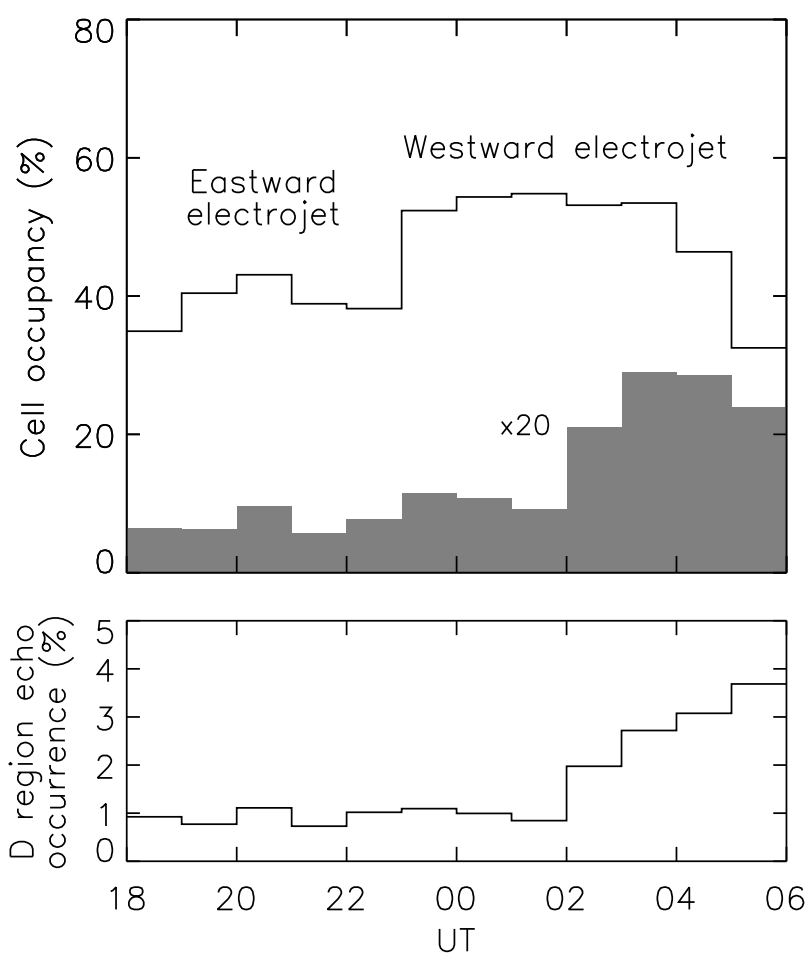

Fig. 5. The UT dependence of the occurrence of E region echoes and $\mathrm{D}$ region echoes. These are measured as field-of-view cell occupancy, the average proportion of radar cells that contain E region echoes (defined as those from an altitude below $150 \mathrm{~km}$, solid curve) and D region echoes (defined as those from an altitude below $100 \mathrm{~km}$ with spectral widths less than $20 \mathrm{~m} \mathrm{~s}^{-1}$, grey bars). The proportion of echoes from the $\mathrm{D}$ region is indicated in the lower panel.

nificant occurrences of the new backscatter population occurred in the post-midnight sector, as reflected in our choice of examples in Fig. 4. To investigate this in more detail, Fig. 5 indicates the UT occurrence of E region echoes (solid curve) and D region echoes (grey bars). This was constructed from the 12 runs of the myopic mode in September 1999 and 2000 , comprising $124 \mathrm{~h}$ of observations and $1.6 \times 10^{6}$ echoes. This is measured as the cell occupancy, the proportion of cells in the near-range field-of-view between gates 10 and 30 that are filled with echoes originating below $150 \mathrm{~km}$ in altitude (E region) and below $100 \mathrm{~km}$ (D region). We set the first range as gate 10 so as not to include the occurrence of meteor echoes which occur only in the very nearest ranges. The bottom panel then shows the proportion of echoes which are from the $\mathrm{D}$ region. The overall echo occurrence is approximately $50 \%$, though higher post-midnight $(60 \%)$ than pre-midnight (40\%) indicating that more backscatter is observed from the westward electrojet than the eastward electrojet. The occurrence of $\mathrm{D}$ region echoes increases dramatically in the morning sector, from $1 \%$ of echoes before 02:00 MLT, up to nearly $4 \%$ of echoes by 06:00 MLT. 




Fig. 6. A comparison of the Doppler shift distribution of E region (solid curve) and D region (grey bars) echoes.

Finally, we investigate the Doppler shift of the echoes in Fig. 6. The occurrence distributions of Doppler shifts in bins $25 \mathrm{~m} \mathrm{~s}^{-1}$ wide are shown for all echoes originating below $150 \mathrm{~km}$ (solid curve) and from below $100 \mathrm{~km}$ with unusually narrow spectra (grey bars). The $\mathrm{E}$ region distribution peaks at $0 \mathrm{~m} \mathrm{~s}^{-1}$, though is broad with wings extending to $\pm 750 \mathrm{~m} \mathrm{~s}^{-1}$, and distinct shoulders at $\pm 400 \mathrm{~m} \mathrm{~s}^{-1}$ corresponding to the ion-acoustic speed and the occurrence of the two-stream instability (Milan and Lester, 2001). There are more echoes at negative Doppler velocities as these originate in the westward electrojet (the radar looks east and Doppler shifts away from the radar are negative) which has a higher scattering occurrence (Fig. 5). The D region distribution also peaks near $0 \mathrm{~m} \mathrm{~s}^{-1}$, but now is much narrower, with $75 \%$ of echoes having Doppler shifts within $\pm 100 \mathrm{~m} \mathrm{~s}^{-1}$ (as opposed to $40 \%$ in the $\mathrm{E}$ region distribution). There are still shoulders in the distribution near the ion-acoustic speed, but these appear to be due to echoes from the E region with erroneous altitude estimates. It is possible that the $\mathrm{D}$ region Doppler shift distribution is shifted towards negative values by approximately $25 \mathrm{~m} \mathrm{~s}^{-1}$.

\section{Discussion}

We have presented examples of an HF radar backscatter population that occurs at altitudes between 80 and $100 \mathrm{~km}$, with echoes which have unusually low spectral widths (less than $20 \mathrm{~m} \mathrm{~s}^{-1}$ ). Such echoes occur predominantly in the postmidnight sector, in association with enhancements of the D region electron density. Such enhancements lead to the attenuation of HF radio signals, often referred to as auroral absorption, which we measure as cosmic noise absorption (CNA). It has also been suggested that this occurs in association with pulsating aurora, which are known to have a hard precipitating energy spectrum (Stenbaek-Nielsen and
Hallinan, 1979; Sandahl et al., 1980), and so are expected to produce enhancement of the $\mathrm{D}$ region electron density. One of our events is certainly associated with pulsating aurora. The backscatter events were observed predominantly between 02:00 to 06:00 MLT, though as the latter marked the end of each observing interval it is possible that the occurrence could continue later into the morning sector.

The local time occurrence of the echoes matches the known local time occurrence of both pulsating aurora and auroral absorption. Pulsating aurora are generally a morning sector, substorm recovery phase phenomenon. Auroral absorption maximizes in the morning sector following substorm onset as energetic electrons injected into the midnight sector drift eastwards under the influence of gradient and curvature drift (e.g. Milan et al., 1996). However, it remains to be determined if all occurrences of $\mathrm{D}$ region backscatter are associated with pulsating aurora, or just more generally with any precipitation event that gives rise to a $\mathrm{D}$ region enhancement. We will address this in future by performing an detailed comparison of such backscatter with optical observations of pulsating aurora.

It is interesting to note in Fig. 2 that after the new lowaltitude echoes appear, the pre-existing population of $\mathrm{E}$ region echoes is no longer observed. It is not clear if this is because (a) the irregularities in the E region are no longer present, (b) the E region echoes are masked by the backscatter from lower altitudes, or (c) the radar signals from the $\mathrm{E}$ region are absorbed during their traversal of the $\mathrm{D}$ region, in the same way that the riometer measures CNA. The second reason (b) seems not to be the case as the transition occurs in association with an overall decrease in the backscatter power of the echoes observed (not shown). In other words, the D region echoes do not dominate over the $\mathrm{E}$ region ones. We can estimate the expected attenuation of the backscatter power of the $\mathrm{E}$ region echoes from the observed CNA, which peaks at $\sim 0.6 \mathrm{~dB}$. D region nondeviative attenuation of HF radio waves of frequency $f$ varies as (e.g. Davies, 1990):

$L(\mathrm{~dB})=8.68 \frac{e^{2}}{2 \varepsilon_{0} m c} \frac{N_{0} \nu_{0} \Delta h}{f^{2}} \approx \frac{N_{0} \nu_{0} \Delta h}{10^{6} f^{2}}$

where the $\mathrm{D}$ region is treated as a slab of thickness $\Delta h$ with mean electron number density and collision frequency $N_{0}$ and $v_{0}$, respectively; the other symbols have their usual meanings. The observed $0.6 \mathrm{~dB}$ of attenuation at $f=30 \mathrm{MHz}$ allows an estimate of the electron density of the $\mathrm{D}$ region to be made: assuming $\Delta h=20 \mathrm{~km}$ and $v_{0}=10^{6} \mathrm{~s}^{-1}, N_{0} \approx 2-$ $3 \times 10^{10} \mathrm{~m}^{-3}$. In addition, the $f^{-2}$ dependence of the absorption indicates that $0.6 \mathrm{~dB}$ of absorption at the riometer operating frequency corresponds to $5 \mathrm{~dB}$ at the radar frequency of $10 \mathrm{MHz}$. We must consider that the radar signals traverse the $\mathrm{D}$ region twice as they propagate to the $\mathrm{E}$ region and back, whereas the riometer measures "one-way" absorption of the cosmic noise. In addition, the radar signals propagate obliquely through the $\mathrm{D}$ region, whereas the riometer beams point more vertically. We might then expect up to $30 \mathrm{~dB}$ of 
attenuation of E region backscatter returns, which is close to their backscatter power prior to the arrival of the pulsating aurora. Hence, it is possible that the disappearance of the $\mathrm{E}$ region echoes is caused by auroral absorption.

The exact mechanism for the generation of the plasma density irregularities from which the radar scatters is uncertain. We now briefly discuss two possible scenarios, in which an ionospheric instability mechanism structures the plasma, and in which the radar returns are due to partial reflection from density variations imposed by structure in the precipitation itself.

The observations suggest that the backscatter appears over a broad range of magnetic aspect angles, in other words that a non-aspect sensitive scattering mechanism is at work. The $\mathrm{D}$ region electron density is sufficiently low (even when enhanced) that refraction of the radar signals will be negligible and straight-line propagation can be assumed. For instance, the refractive index of the $\mathrm{D}$ region is given by (e.g. Davies, 1990):

$\mu^{2}=1-\frac{f_{p}^{2}}{f^{2}}$

where $f_{p}$ is the plasma frequency in a plasma of electron density $N_{0}$ (estimated above) given by

$f_{p}=\sqrt{\frac{N_{0} e^{2}}{4 \pi^{2} \varepsilon_{0} m}}$.

At the radar operating frequency of $10 \mathrm{MHz}, \mu \approx 0.99$. Application of Snell's Law indicates that for a radar ray incident on the $\mathrm{D}$ region at an angle of $60^{\circ}$ to the vertical, the ray is refracted by approximately $1^{\circ}$ towards the horizontal, that is, by a negligible amount. Hence we can estimate the aspect angle of the radar beams at the points at which scatter is observed. The echoes appear over an extended region of the field-of-view, between ranges of 200 and $500 \mathrm{~km}$. Assuming that the scatter originates at $90 \mathrm{~km}$ altitude, this implies that echoes are observed from locations at which the radar signals are propagating at angles between $10^{\circ}$ and $25^{\circ}$ to the horizontal, implying aspect angles as high as $25^{\circ}$. Rüster and Schlegel (1999) demonstrated the observation of low altitude scatter by a $50 \mathrm{MHz}$ radar at aspect angles as high as $90^{\circ}$. Robinson and Schlegel (2000) proposed an instability mechanism for creating low altitude, non aspect sensitive irregularities, to account for these observations. That mechanism relied on electron precipitation to destabilize the lower ionosphere, which is consistent with our observed association with pulsating aurora and cosmic noise absorption. We should note that high aspect angle backscatter has previously been observed at $\mathrm{HF}$, but at altitudes above $120 \mathrm{~km}$ and is thought to be associated with an ionospheric instability mechanism (Milan et al., 2004; Drexler and St.-Maurice, 2005).

On the other hand, the D region echoes observed are exceptionally narrow, with spectral widths akin to those of meteor scatter. This could suggest that the decorrelation of the radar signals is governed by ambipolar diffusion of blobs of plasma deposited by precipitation rather than irregularity growth and decay rates dictated by an ionospheric instability mechanism (Milan et al., 2001). Hall et al. (1997) proposed that the spectral width of echoes scattering from diffusing meteor trails should be $\Delta v=8 \pi D / \lambda$, where $D$ is the ambipolar diffusion coefficient and $\lambda$ is the radar wavelength, which is $30 \mathrm{~m}$ in the present case. If we propose a similar scattering mechanism then our observed spectral widths of $20 \mathrm{~m} \mathrm{~s}^{-1}$ and less are associated with values of $D$ less than approximately $20 \mathrm{~m}^{2} \mathrm{~s}^{-1}$. This occurs at altitudes of $100 \mathrm{~km}$ and below (Hall et al., 1997), consistent with our altitude estimates from the interferometer. It is possible, then, that the backscatter occurs from spatial inhomogeneities in the precipitation giving rise to irregularities in the $\mathrm{D}$ region. If the backscatter process is coherent, then these irregularities are of a spatial scale similar to the wavelength of the radar signals, that is of the order of $10 \mathrm{~m}$. Alternatively, if the density gradients are sufficiently high, a partial reflection mechanism could be at work. This mechanism is also consistent with the non aspect sensitivity of the observed scatter.

\section{Conclusions}

During the recovery phase of substorms, in concert with pulsating aurora and enhancement of the D region by energetic precipitation, the latter resulting in cosmic radio noise absorption, the SuperDARN radars can observe backscatter echoes from heights between 80 and $100 \mathrm{~km}$, significantly below the altitude at which $\mathrm{E}$ region scatter is seen. The echoes are exceptionally narrow, and have Doppler shifts in general below $100 \mathrm{~m} \mathrm{~s}^{-1}$. The scatter appears to arise in regions where the aspect angle is as high as $25^{\circ}$, as the $\mathrm{D}$ region electron density is insufficient to refract the radar signals to orthogonality with the magnetic field.

It is not clear if the irregularities from which the radars scatter are created by structured precipitation or are due to an ionospheric instability process. However, the narrow spectra perhaps favour a mechanism in which blobs of plasma are deposited at low altitudes by precipitation, in a manner akin to the ablation of meteors observed as meteor scatter.

These D region echoes are a relatively common feature of SuperDARN measurements during substorm recovery phase. The echo characteristics, especially their low Doppler shift, are such that they could contaminate studies of the ionospheric flow excited by substorms. Clearly, it is important that these echoes are properly identified during such studies as not arising from the $\mathrm{F}$ region. On the other hand, they provide an indication of the occurrence of energetic particle precipitation, and as such can help diagnose the precipitation characteristics during substorm and non-substorm times.

Acknowledgements. We would like to thank T. Saemundsson from the Science Institute and the University of Iceland for invaluable help in organizing the Tjörnes optical observing campaigns. The 
Sub-Auroral Magnetometer Network (SAMNET) is operated by the Department of Communications Systems at Lancaster University (UK) and is funded by the Science and Technology Facilities Council (STFC).

Topical Editor M. Pinnock thanks two anonymous referees for their help in evaluating this paper.

\section{References}

Chisham, G., Lester, M., Milan, S. E., Freeman, M. P., Bristow, W. A., Grocott, A., McWilliams, K. A., Ruohoniemi, J. M., Yeoman, T. K., Dyson, P. L., Greenwald, R. A., Kikuchi, T., Pinnock, M., Rash, J. P. S., Sato, N., Sofko, G. J., Villain, J.P., and Walker, A. D. M.: A decade of the Super Dual Auroral Radar Network (SuperDARN): Scientific achievements, new techniques and future directions, Surv. Geophys., 28, 33-109, doi:10.1007/s10712-007-9017-8, 2007.

Davies, K.: Ionospheric Radio, IEE Electromagnetic Waves Series 31, Peter Peregrinus Ltd., London, 1990.

Drexler, J. and St-Maurice, J.-P.: A possible origin for large aspect angle "HAIR" echoes seen by SuperDARN radars in the E region, Ann. Geophys., 23, 767-772, 2005, http://www.ann-geophys.net/23/767/2005/.

Greenwald, R. A., Baker, K. B., Dudeney, J. R., Pinnock, M., Jones, T. B., Thomas, E. C., Villain, J.-P., Cerisier, J.-C., Senior, C., Hanuise, C., Hunsucker, R. D., Sofko, G., Koehler, J., Nielsen, E., Pellinen, R., Walker, A. D. M., Sato, N., and Yamagishi, H.: DARN/SuperDARN: A global view of the dynamics of highlatitude convection, Space Sci. Rev., 71, 761-796, 1995.

Haldoupis, C.: A review on radio studies of the auroral E-region ionospheric irregularities, Ann. Geophys., 7, 239-258, 1989, http://www.ann-geophys.net/7/239/1989/.

Hall, G. E., MacDougall, J. W., Moorcroft, D. R., St.-Maurice, J.P., Manson, A. H., and Meek, C. E.: Super Dual Auroral Radar Network observations of meteor echoes, J. Geophys. Res., 102, 14603-14 614, 1997.

Milan, S. E. and Lester, M.: A classification of spectral populations observed in HF radar backscatter from the E region electrojets, Ann. Geophys., 19, 189-204, 2001, http://www.ann-geophys.net/19/189/2001/.

Milan, S. E., Jones, T. B., Lester, M., Warrington, E. M., and Reeves, G. D.: Substorm correlated absorption on a $3200 \mathrm{~km} \mathrm{HF}$ propagation path, Ann. Geophys., 13, 182-190, 1996, http://www.ann-geophys.net/13/182/1996/.
Milan, S. E., Jones, T. B., Robinson, T. R., Thomas, E. C., and Yeoman, T. K.: Interferometric evidence for the observation of ground backscatter originating behind the CUTLASS coherent HF radars, Ann. Geophys., 15, 29-39, 1997a, http://www.ann-geophys.net/15/29/1997/.

Milan, S. E., Yeoman, T. K., Lester, M., Thomas, E. C., and Jones, T. B.: Initial backscatter occurrence statistics from the CUTLASS HF radars, Ann. Geophys., 15, 703-718, 1997b, http://www.ann-geophys.net/15/703/1997/.

Milan, S. E., Lester, M., Sato, N., and Takizawa, H.: On the altitude dependence of the spectral characteristics of decametrewavelength $\mathrm{E}$ region backscatter and the relationship with optical auroral forms, Ann. Geophys., 19, 205-217, 2001, http://www.ann-geophys.net/19/205/2001/.

Milan, S. E., Lester, M., and Sato, N.: Multi-frequency observations of HF radar E region aurora, Ann. Geophys., 21, 761-777, 2003, http://www.ann-geophys.net/21/761/2003/.

Milan, S. E., Lester, M., Yeoman, T. K., Robinson, T. R., Uspensky, M. V., and Villain, J.-P.: HF radar observations of high-aspect angle backscatter from the E region, Ann. Geophys., 22, 829847, 2004, http://www.ann-geophys.net/22/829/2004/.

Ogawa, T., Arnold, N. F., Kirkwood, S., Nishitani, N., and Lester, M.: Finland HF and Esrange MST rdar observations of polar mesospheric summer echoes, Ann. Geophys., 21, 1047-1055, 2003, http://www.ann-geophys.net/21/1047/2003/.

Robinson, T. R. and Schlegel, K.: The generation of non aspect sensitive plasma density irregularities by field aligned drifts in the lower ionosphere, Ann. Geophys., 18, 799-806, 2000, http://www.ann-geophys.net/18/799/2000/.

Rüster, R. and Schlegel, K.: Non-magnetic aspect sensitive auroral echoes from the lower E region observed at $50 \mathrm{MHz}$, Ann. Geophys., 17, 1284-1292, 1999, http://www.ann-geophys.net/17/1284/1999/.

Sandahl, I., Eliasson, L., and Lundin, R.: Rocket observations of precipitating electrons over a pulsating aurora, Geophys. Res. Lett., 7, 309-312, 1980.

Stenbaek-Nielsen, H. C. and Hallinan, T. J.: Pulsating aurora: Evidence for collisional thermalzation of precipitating electrons, J. Geophys. Res., 84, 3257-3271, 1979. 